\title{
Review Article \\ Developing Multipurpose Reproductive Health Technologies: An Integrated Strategy
}

\author{
P. F. Harrison, ${ }^{1,2}$ A. Hemmerling, ${ }^{1,3}$ J. Romano, ${ }^{4}$ K. J. Whaley, ${ }^{5}$ and B. Young Holt ${ }^{1}$ \\ ${ }^{1}$ Coalition for Advancing Multipurpose Innovations (CAMI)/Public Health Institute, USA \\ ${ }^{2}$ AVAC, Global Advocacy for HIV Prevention, New York, USA \\ ${ }^{3}$ University of California, 50 Beale Street, Suite 1200, San Francisco, CA 94105, USA \\ ${ }^{4}$ NWJ Group, LLC, USA \\ ${ }^{5}$ Mapp Biopharmaceutical, San Diego, USA
}

Correspondence should be addressed to A. Hemmerling; ahemmerling@globalhealth.ucsf.edu

Received 31 October 2012; Revised 15 January 2013; Accepted 16 January 2013

Academic Editor: Craig R. Cohen

Copyright (c) 2013 P. F. Harrison et al. This is an open access article distributed under the Creative Commons Attribution License, which permits unrestricted use, distribution, and reproduction in any medium, provided the original work is properly cited.

\begin{abstract}
Women worldwide confront two frequently concurrent reproductive health challenges: the need for contraception and for protection from sexually transmitted infections, importantly HIV/AIDS. While conception and infection share the same anatomical site and mode of transmission, there are no reproductive health technologies to date that simultaneously address that reality. Relevant available technologies are either contraceptive or anti-infective, are limited in number, and require different modes of administration and management. These "single-indication" technologies do not therefore fully respond to what is a substantial reproductive health need intimately linked to pivotal events in many women's lives. This paper reviews an integrated attempt to develop multipurpose prevention technologies_-MPTs"- products explicitly designed to simultaneously address the need for both contraception and protection from sexually transmitted infections. It describes an innovative and iterative MPT product development strategy with the following components: identifying different needs for such technologies and global variations in reproductive health priorities, defining "Target Product Profiles" as the framework for a research and development "roadmap," collating an integrated MPT pipeline and characterizing significant pipeline gaps, exploring anticipated regulatory requirements, prioritizing candidates for problem-solving and resource investments, and implementing an ancillary advocacy agenda to support this breadth of effort.
\end{abstract}

\section{Introduction}

The combined burden of maternal and infant mortality and morbidity produced by unintended pregnancies and sexually transmitted infections-individually and as a consequence of their multiple interactions-is compelling in its volume, extent, and complexity. For an array of behavioral, biological, physiological, and sociocultural and political reasons, most of that burden falls on women in developing countries. In those countries, of the 80 million unintended pregnancies estimated for 2012, 63 million will occur among the 222 million women defined as having an "unmet need" for modern contraception [1]. Those unintended pregnancies will, in turn, result in 30 million unplanned births; 10 million miscarriages, including stillbirths; and 40 million abortions, of which one-third to one-half will be unsafe. Women aged 15-19 are at particular risk of these events [2].

Sexually transmitted infections (STIs) further compound these burdens, with which they are relentlessly intertwined. The World Health Organization estimates that 448 million new cases of the curable STIs (trichomoniasis, chlamydia, gonorrhea, and syphilis) occur annually in adults aged 15-49 years [3]. Cases of the major incurable viral diseases-genital herpes (HSV-2), human papillomavirus (HPV), and HIV-1account for an even greater burden of both morbidity and mortality. The estimated number of people aging $15-49$ years living with HSV-2 worldwide in 2003 was 536 million, with overall prevalence higher in women than in men [4]. Each year an estimated 493,000 women are diagnosed with cervical cancer, largely attributable to HPV infection; over 273,000 die 
from the disease, 234,000 of those in developing regions [5]. Lastly, there is HIV, with 2.7 million new infections in 2010, of which, in many regions and subpopulations, women account for over half.

Over 20 years ago, a seminal review described the relationship between the "classical" STIs and HIV-1 as an essentially lethal "epidemiologic synergy" [6]. The authors presented persuasive evidence that both ulcerative and nonulcerative STIs significantly promoted HIV transmission by augmenting HIV infectiousness and susceptibility, concluding that STI treatment should therefore be an essential component of HIV prevention strategies. Yet, while subsequent studies continued to document and elucidate those relationships, interest in addressing the relationship between STIs and HIV-1 waned, primarily because it has "proven nearly impossible to reduce the spread of HIV-1 through directed or empirical treatment of STDs" [7].

Addressing contraception and STI prevention in meaningfully coordinated fashion has had limited success, even given potential cost savings [8]. Typically, women must seek care for contraception and HIV prevention from separate health facilities and different providers, and examples of truly functional integration of HIV, STI, and family planning services remain rare. Such efforts can be organizationally and/or financially difficult to implement and HIV-associated stigma may act as an additional barrier.

The premise of the work reported here is that multipurpose prevention technologies - "MPTs"-addressing more than a single reproductive health indication with a single administration would offer an additional route to integrated reproductive health. Potential components for such products exist, some already commercially available; new components and formulations are also likely to be required. MPTs could comprise combinations of HIV prevention technologies with agents having contraceptive activity; available contraceptives and agents active against HIV; single drugs targeting more than one indication; totally new drug combinations or combinations of drugs and devices; and/or multi-indication vaccines.

\section{Materials and Methods}

This paper describes an innovative process designed to advance the development of MPTs through systematic, iterative consideration of, first, the key components of a standard product development pathway and, second, different product requirements in different user populations. The organization of the account that follows below responds to the general categories proposed for the COREQ, the checklist of consolidated criteria for reporting qualitative research [9].

2.1. Research Teams. Advancing the MPT concept was expected to be scientifically, technologically, and practically challenging. Mobilization of the scientific and financial resources required for MPT development would demand a sound evidence-based argument for the need for MPTs and their plausibility as a product category, plus an integrated mix of expertise and advocacy. To that end, the Initiative for Multipurpose Prevention Technologies for Reproductive Health (IMPT) was founded in 2009 as a global coalition of multidisciplinary and multinational stakeholders, scientists, policy-makers, advocates, donors, and product developers [57]. Housed at CAMI (Coalition Advancing Multipurpose Innovations) in California, USA, the IMPT was organized as a nonaligned convener for affiliates and as an umbrella for working groups and teams with specific research and advocacy responsibilities.

The activities of the Initiative and its colleagues focus in three areas:

(1) defining an integrated MPT product pipeline and scientific agenda, as guidance for donors, product developers, regulators, and advocates about MPT scientific priorities and needs;

(2) exploring the associated regulatory pathways and anticipated needs around delivery of and access to such products;

(3) designing and implementing a strategy for communication, advocacy, and outreach to raise global awareness around MPTs as a prospective public health product.

The emphasis in this paper is on the first two of these activities and the teams formed sequentially for their implementation: the Think Tank, Drug-Drug/Drug-Device Working Group, Multipurpose Reproductive Health Vaccine Working Group, and Scientific Agenda Working Group (SAWG). The CAMI Advisory Committee and Management Group was led by the authors of this paper and was responsible for the overall conceptual guidance and management of the entire process. Figure 1 presents the chronology of team formation and key MPT process-related activities; Table 1 in the section on study design summarizes the objectives and methodology used by each team and their contributions to the strategy process.

\section{Study Design}

3.1. Theoretical Framework. The novelty, breadth, and complexity of the MPT concept required a comparably broad and complex methodology. The Advisory Group opted for an iterative research and advocacy strategy comprising focused consultations, surveys, qualitative data-gathering, and pipeline analysis, all informed by input from scientists, product developers, representatives from relevant geographic regions, and donors. The strategy objectives were to assess the scientific feasibility of the MPT concept, develop an "MPT Target Product Profile," and define and prioritize a scientific agenda for MPT research and development that would inform MPT investment, policy, and advocacy.

Assessing the potential of each MPT candidate according to the desired TPP was expected to (1) identify the nature and magnitude of required resources for advancing the most promising pipeline candidates, (2) flag unproductive redundancies in the overall pipeline, and (3) avoid duplication of effort or development of products that fail to meet the minimum requirements of the TPP. The intended output 
Table 1: Study design components.

\begin{tabular}{|c|c|c|}
\hline $\begin{array}{l}\text { Teams and } \\
\text { associated } \\
\text { activities* }\end{array}$ & Tasks and deliverables & Data collection approach \\
\hline $\begin{array}{l}\text { CAMI Advisory } \\
\text { Committee and } \\
\text { Core Management } \\
\text { Group }\end{array}$ & $\begin{array}{l}\text { Overall design and } \\
\text { management of strategic } \\
\text { process }\end{array}$ & $\begin{array}{l}\text { Regular telephonic and } \\
\text { internet consultation, } \\
\text { document preparation, and } \\
\text { review }\end{array}$ \\
\hline Think Tank ${ }^{*}$ & $\begin{array}{l}\text { Answer } 2 \text { questions: } \\
\text { (i) Is MPC concept } \\
\text { scientifically feasible? } \\
\text { (ii) If so, what is most } \\
\text { logical and effective way to } \\
\text { organize and prioritize the } \\
\text { scientific agenda for MPT } \\
\text { R\&D? } \\
\text { (Results to be discussed at } \\
\text { International MPT } \\
\text { Symposium, November } \\
\text { 2011) }\end{array}$ & $\begin{array}{l}\text { Document review and } \\
\text { consultation (May 2011) } \\
\text { (i) Review of ideal } \\
\text { characteristics for } \\
\text { populations most likely to } \\
\text { benefit from MPTs } \\
\text { (ii) Review of pipeline of } \\
\text { relevant technologies } \\
\text { (iii) Preliminary definition } \\
\text { of research needs, gaps, } \\
\text { obstacles for each MPT } \\
\text { component }\end{array}$ \\
\hline
\end{tabular}

\begin{tabular}{ll}
\hline & \\
& \\
& $\begin{array}{l}\text { Implement strategy to: } \\
\text { (i) Select and refine TPP } \\
\text { critical attributes and } \\
\text { appropriate parameter }\end{array}$ \\
& ranges for high-impact \\
Drug-Drug and & MPTs in these product \\
Drug-Device & categories \\
Working Group & (ii) Expand understanding \\
& of regional needs and \\
& priorities for MPT \\
development
\end{tabular}

"Snowball" series of
surveys, ePolls, qualitative
interviews, consultations,
invited presentations,
consultations, and reviews
of successive iterations of
TPP parameters and
criteria (March
2011-January 2012)

28 representatives from businesses, foundations, universities, nonprofit organizations, US government agencies (USAID, NIH, FDA)

(i) Core strategy management group $(N=6)$

(ii) Entire CAMI Advisory Committee $(N=24)$
Process contributions (summary conclusions/material outputs)

Series of meeting reports, circulation of survey findings, web posting of presentations, conference convening

Conclusions:

(i) MPTs deemed feasible, though scientifically challenging

(ii) Recommended adoption of Target Product Profile methodology for MPTs

(iii) Agreed to form two teams to develop specific TPPs for (a) combination drug and drug/device MPTs and (b) multipurpose vaccines

Key populations: reproductive health and HIV research experts and advocates from Asia, Africa, Europe, United States, including

(i) 593 US health care providers (Association for Reproductive Health Professionals (ARHP) 2011 Conference)

(ii) 289 African health care providers (International Family Planning (ICFP) 2011 Conference) (iii) 120 participants, MPT 2011 Symposium

\begin{tabular}{|c|c|c|c|c|}
\hline $\begin{array}{l}\text { Multipurpose } \\
\text { Vaccine Working } \\
\text { Group }\end{array}$ & $\begin{array}{l}\text { (i) Elicit ideas for } \\
\text { multipurpose reproductive } \\
\text { health vaccines } \\
\text { (ii) Develop consensus } \\
\text { Target Product Profile } \\
\text { (iii) Discuss timeline for } \\
\text { MPT vaccine development }\end{array}$ & $\begin{array}{l}\text { (i) "Request for MPT } \\
\text { Concepts" formulated, } \\
\text { reviewed, emitted } \\
\text { (ii) Teleconference process } \\
\text { to develop Target Product } \\
\text { Profile for MPT } \\
\text { reproductive health } \\
\text { vaccines }\end{array}$ & $\begin{array}{l}N=15 \mathrm{MPT} \text { vaccine } \\
\text { researchers and potential } \\
\text { developers }\end{array}$ & $\begin{array}{l}13 \text { submissions received } \\
\text { based on active } \\
\text { immunization, passive } \\
\text { immunization, } \\
\text { adenovirus-vectored } \\
\text { antibodies, and MPT } \\
\text { vaccine development } \\
\text { strategies }\end{array}$ \\
\hline $\begin{array}{l}\text { Scientific Agenda } \\
\text { Working Group } \\
\text { (SAWG) }\end{array}$ & $\begin{array}{l}\text { (i) Use TPPs developed by } \\
\text { the product-specific } \\
\text { working groups as } \\
\text { framework for } \\
\text { (ii) Characterizing the } \\
\text { MPT pipeline from } \\
\text { discovery through } \\
\text { regulatory approval } \\
\text { (iii) Prioritizing promising } \\
\text { candidates }\end{array}$ & $\begin{array}{l}\text { (i) Agenda-driven } \\
\text { conference calls to review } \\
\text { successive iterations of } \\
\text { TPPs and survey responses } \\
\text { (ii) Convening of experts } \\
\text { charged with critiquing and } \\
\text { debating SAWG draft to } \\
\text { formally review SAWG } \\
\text { recommendations }\end{array}$ & $\begin{array}{l}\text { (i) Respondents to MPT } \\
\text { Product Profiles Survey } \\
\text { (ii) } 35 \text { experts from } \\
\text { pharmaceutical companies, } \\
\text { academic institutions, } \\
\text { national regulatory } \\
\text { authorities, global drug } \\
\text { delivery }\end{array}$ & $\begin{array}{l}\text { (i) SAWG } \\
\text { recommendations and } \\
\text { priorities endorsed } \\
\text { (ii) Feedback and } \\
\text { recommendations } \\
\text { regarding challenges, risks, } \\
\text { and strategies to be } \\
\text { considered }\end{array}$ \\
\hline
\end{tabular}

Consensus derived from each survey analyzed to construct consensus TPP for presentation, discussion, feedback from participants in International MPT Symposium (November 2011, Washington, DC) and $>60$ participants at Global Forum on Multipurpose Prevention Technologies (London, UK, January 2012) ${ }^{*}$ for discussion 13 submissions received based on active immunization, passive antibodies, and vaccine development (i) SAWG regarding challenges, risks, es to $b$ 
TABle 1: Continued.

\begin{tabular}{|c|c|c|c|c|}
\hline $\begin{array}{l}\text { Teams and } \\
\text { associated } \\
\text { activities* }\end{array}$ & Tasks and deliverables & Data collection approach & Participants & $\begin{array}{l}\text { Process contributions } \\
\text { (summary } \\
\text { conclusions/material } \\
\text { outputs) }\end{array}$ \\
\hline & $\begin{array}{l}\text { (iv) Analyzing overall } \\
\text { pipeline status and gaps } \\
\text { (v) Exploring associated } \\
\text { regulatory implications }\end{array}$ & & $\begin{array}{l}\text { Efforts, and countries with } \\
\text { greatest need for MPT } \\
\text { products (Product } \\
\text { Prioritization Stakeholder } \\
\text { Meeting, October 2012) }\end{array}$ & \\
\hline
\end{tabular}

Reports for the starred activities are available at http://www.cami-health.org [10-13].

TABLE 2: TPP parameters for prioritizing MPT development.

\begin{tabular}{|c|c|c|}
\hline Parameter & Preferred criteria & Minimally acceptable criteria \\
\hline Indications & $\begin{array}{l}\text { HIV + contraception } \\
\text { (high emphasis for sub-Saharan African markets) } \\
\text { (high emphasis for sub-Saharan African markets) }\end{array}$ & $\begin{array}{l}\text { HIV + HSV (high emphasis for non-LDC markets) } \\
\text { contraception + STI (high emphasis for Indian and } \\
\text { Chinese markets) } \\
\text { BV, HPV, and TV (moderate emphasis) } \\
\text { GC + syphilis (minimal emphasis) }\end{array}$ \\
\hline $\begin{array}{l}\text { Route of } \\
\text { administration }\end{array}$ & Vaginal rings & Oral pills, injectables \\
\hline $\begin{array}{l}\text { Dosage form and } \\
\text { schedule }\end{array}$ & $\begin{array}{l}\text { Sustained release (1-12 months) } \\
\text { Pericoital } \\
\text { Fast-acting } \\
\text { Topical (vaginal) }\end{array}$ & $\begin{array}{l}\text { Daily } \\
\text { Oral }\end{array}$ \\
\hline \multicolumn{3}{|l|}{ Efficacy: } \\
\hline (i) HIV & $80 \%$ & $40 \%-70 \%$ \\
\hline (ii) Contraception & $>$ Current levels per contraceptive of $>90 \%$ & Current levels with recommended use \\
\hline (iii) STI & $>80 \%$ & $40 \%$ \\
\hline Storage conditions & $>40^{\circ} \mathrm{C} / 75 \% \mathrm{RH}$ & $\begin{array}{l}15-30^{\circ} \mathrm{C} / 65 \% \mathrm{RH} \text { for topical/pills } \\
\text { Refrigeration at } 4^{\circ} \mathrm{C} \text { for injectables }\end{array}$ \\
\hline Shelf life & $>36$ months & 24 months \\
\hline $\begin{array}{l}\text { Yearly product } \\
\text { cost/user }\end{array}$ & $<$ US\$ 50 & $<$ US\$ 100 \\
\hline Disposal/waste & Concealable, biodegradable user disposal & $\begin{array}{l}\text { Controlled disposal (to include all associated materials } \\
\text { (implant, injectables)) }\end{array}$ \\
\hline Adherence & $>80 \%$ of users follow prescribed regimen & $>60 \%$ of users follow prescribed regimen \\
\hline Time to licensure & 5 years & $8-12$ years (by 2020$)$ \\
\hline Reversibility & $\begin{array}{l}0-24 \text { hours for oral, topical, sustained-release methods } \\
14 \text { days for implants, injectables }\end{array}$ & $\begin{array}{l}\text { 14-30 days for oral, topical, sustained-release methods } \\
90 \text { days for implants, injectables }\end{array}$ \\
\hline
\end{tabular}


TABLE 3: Multipurpose RH Vaccine Working Group: active immunization concepts.

\begin{tabular}{ll}
\hline Indication and mechanism & Immunogen, adjuvant, and delivery mode \\
\hline $\begin{array}{l}\text { HIV-1, HPV } \\
\begin{array}{l}\text { Stimulation of humoral and cellular immune } \\
\text { response }\end{array}\end{array}$ & $\begin{array}{l}\text { DNA systemic (IM); subunit mucosal (intranasal, sublingual, and vaginal), CM } \\
\text { cellulose (mucoadhesive) }\end{array}$
\end{tabular}

HIV-1, HSV-2, and HPV

Targeted induction of broadly neutralizing antibodies (systemic)

HSV, HPV, and HIV

Maintain protective concentrations of cervicovaginal antibodies and/or detectable pathogen specific T-cells

\section{HSV, HIV}

Sustained protective levels of antibody and cell-mediated immunity

\begin{tabular}{l} 
HPV, HBV \\
Systemic and mucosal neutralizing antibodies \\
\hline HSV, HIV, and HPV \\
Systemic and mucosal immune responses \\
\hline HPV, sperm (immunocontraceptive can be \\
provided separately); antibodies in fallopian tubes \\
and in cervicovaginal mucus plus systemic \\
antibodies and cell-mediated immunity \\
\hline HIV, HSV \\
Dual-purpose HPV (multiple types) vaccine plus \\
griffithsin microbicide (HIV, HSV)
\end{tabular}

HSV, HIV

Systemic and mucosal protective concentrations of neutralizing antibodies
Synthesized and chemically modified peptide; Advax adjuvant; injected liquid

Intravaginal tampon delivery of a nanoemulsion vaccine containing recombinant HSV-2 glycoprotein D and recombinant HPV 16 and 18 L1 protein and HIV glycoprotein 120

Subunit trimeric gp140 and HSV gD; versatile adjuvant system (PLA-NPs), systemic liquid formulation, and mucoadhesive gel carrying both antigens and immunostimulatory molecules to the same dendritic cell (prevents systemic inflammatory responses)

Virus-like particle (VLP) subunits, MPL or aloe-derivative adjuvant, nasal prime/boost (systemic prime/nasal boost)

DNA or subunit prime with HPV VLPs, gD, gp120 (intramuscular); lactococcus cocktail expressing gD, HPV E6/E7, HIV gag for mucosal boost (tablet)

Salmonella vectored subunits: (a) L1 capsomeres (possibly with L2 peptide), (b) cocktail of sperm antigens; oral tablet

Codelivery of immunogens (trimeric gp140 boosts following DNA prime), and microbicides ( $1 \%$ tenofovir or dapivirine) via an intravaginal ring. Mucosal adjuvant is R848 (a TLR 7/8 agonist) to sustain mucosal memory

L2 epitope fusion with griffithsin (immunogen/adjuvant); intravaginal ring (or PVA film) for burst release of HPV vaccine (L2-griffithsin fusion protein) and sustained release of griffithsin as a microbicide

$\mathrm{gD} / \mathrm{Fc}$ fusion protein, gp41 anti-idiotype; nasal prime delivered with dry inhaler; cervicovaginal boost delivered as film; FcRn-mediated transport across epithelium was a "road map" permitting researchers, policy-makers, and donors to make decisions about next research steps and investments along the entirety of the MPT research and development pathway and identify the potential for efficiencies that might be achieved by strategic collaborations among researchers and developers. Such a review process and the resulting road map was expected to support the best alignment of technologically feasible MPTs with products identified as "ideal" by women and health care providers in regions and populations that would most benefit from multipurpose prevention technologies intended to foster and support improved overall reproductive health.

3.1.1. MPT Target Product Profile. Adoption of this methodology as a major organizing concept for the MPT strategy emerged from the deliberations of the May 2011 MPT Think Tank (Table 1), against a background of increasing interest among major health and development donors in Target Product Profile (TPP) approaches. While variously defined and applied by the pharmaceutical industry and the US Food and Drug Administration, the TPP is a goal-oriented template for assessing and prioritizing candidate biomedical products in terms of their development progress and potential and, in some cases, market prospects and likely impact $[56,58]$. Each MPT strategy team was asked to adapt that basic TPP concept by selecting the attributes, parameters, and associated criteria for MPT products that would offer the highest potential public health impact for their putative user populations, responsiveness to the unmet needs of those populations, and satisfaction of the major MPT objective: contraception and prevention of HIV and non-HIV STIs simultaneously delivered in a variety of modalities.

3.1.2. Product Prioritization. Construction of Target Product Profiles for MPTs involved successive prioritizations of their main elements: primary indications (HIV prevention/contraception, HIV/STI prevention, and STI prevention/contraception; routes of administration and dosage forms; product attributes and parameters (e.g., stability, infrastructure needs, reversibility); and safety, efficacy, and potential for uptake. These individual prioritizations would then contribute to a "consensus TPP" that could shape general development priorities and fundamental design targets that would, in turn, guide funder investment prioritization and 


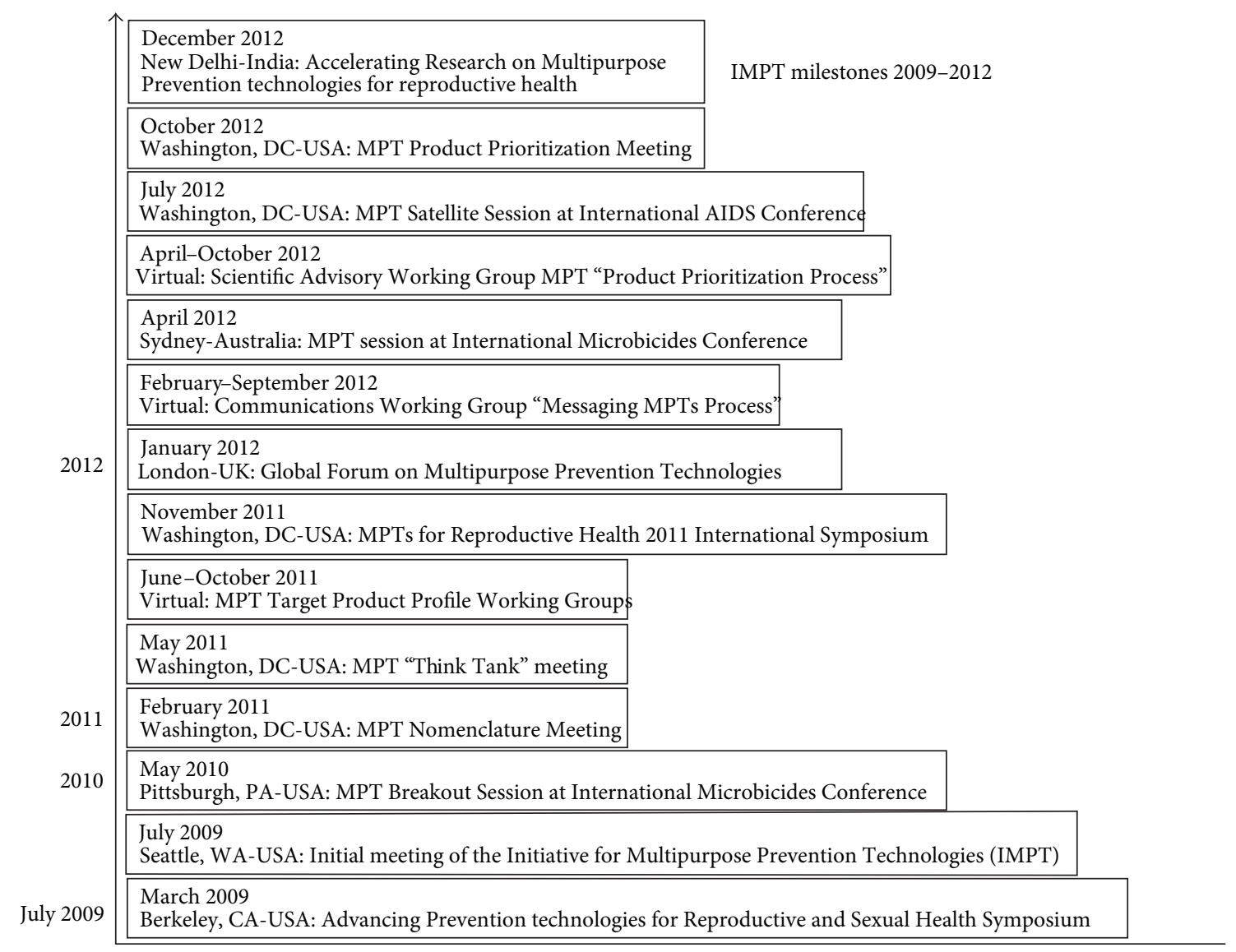

Figure 1: MPT Strategic Milestones 2009-2012.

developer R\&D focus. The process would include compilation of a comprehensive list of candidate MPT-related products and product components, followed by interrelated evaluations for development feasibility, number of candidates per product type, "fit" with general TPP findings, and input from the contraceptive field. This work would be implemented by the Scientific Agenda Working Group (SAWG) and its Product Prioritization subgroup; a similar process would occur in the Multipurpose Reproductive Health Vaccine Working Group.

\subsubsection{Understanding Regional Needs and Priorities for MPT} Development. MPT need and demand would necessarily be affected by the fact that global unmet need and demand for modern contraception are quite variable, as are the epidemiological profiles of HIV and STI incidence, prevalence, and contribution to overall burdens on women's health. Thus the MPT prioritization process would have to take into account the types of target populations in specific geographic regions most likely to benefit from MPTs and be interested in using them.

While the MPT strategy had steadily incorporated perspectives from those regions, the principal methodological contribution to this component was the January 2012 Global Forum on MPTs, which convened 60 participants from Africa, the Caribbean, China, Europe, India, United Kingdom, and the United States to elicit international multisectoral input into draft TPPs, extend consideration of critical path for regulatory approval of MPTs beyond the US Food and Drug Administration (USFDA) to other regional regulatory authorities, encourage global perspective and international support for MPTs, and seek consensus on next steps. The results of this process component are summarized below in Table 5 .

\section{Results: Findings and Analysis}

4.1. Primary Indications for MPT Drug-Drug and Drug-Device Combinations. Across working groups and respondents to different data-gathering approaches, consensus emerged that the most critical parameter in the construction of an MPT Target Product Profile was the combination of indications to be met by a given product, that is, contraception, HIV prevention, and/or prevention of non-HIV-STIs. Overall, the combination of HIV prevention and contraception was assigned the highest priority, followed closely by HIV + HSV. Non-HIV STIs were variously prioritized in terms of relevance for HIV transmission, technical feasibility, epidemiological burden, and effectiveness of available treatments. 
TABle 4: Reproductive Health Consensus Target Product Profile for MPT Vaccines.

\begin{tabular}{ll}
\hline Parameter & Optimally preferred \\
\hline $\begin{array}{l}\text { Indication and } \\
\text { mechanism }\end{array}$ & $\begin{array}{l}\text { HSV HIV, HPV } \\
\text { concentrations of neutralizing } \\
\text { antibodies (and cell-mediated } \\
\text { immunity) }\end{array}$ \\
Target population & $\begin{array}{l}\text { Women/girls: developed and } \\
\text { developing regions }\end{array}$ \\
Immunogen, & Well-characterized immunogens (but \\
adjuvant, and & range of adjuvants and delivery modes \\
delivery modes & Pharmacy or self-administered boosts \\
User-action & Mucosal boost schedule uncertain \\
Boost schedule & HSV (70-90\%); HIV (70-90\%); HPV \\
Typical use efficacy & (>95\%) \\
Side effect profile & Minimal \\
Additional benefits & Versatile production platform \\
Shelf life & Years \\
Storage needs & No cold chain required \\
Price & \$1/dose \\
Infrastructure & Pharmacy
\end{tabular}

Variability among informant populations did produce noteworthy differences in rankings. Comparison of findings from the surveys among US and African reproductive health care providers (Table 1 ) found that 66 percent of African providers ranked unintended pregnancy + HIV as of highest priority, while the same percentage of US providers ranked unintended pregnancy + non-HIV STIs as the highestpriority target indication. HPV was ranked as the highestpriority non-HIV STI by both survey populations (75 percent and 68 percent of African and US providers, resp.). While response volumes from China and India were not high, the combination of contraception + non-HIV STIs appeared to command the most interest as MPT candidates for those markets.

4.2. TPP Parameters for Prioritizing MPT Development. The consensus Target Product Profile for MPTs comprised a defined set of parameters with associated "preferred" and "minimally acceptable" criteria that formed the architecture for determining what must matter most for MPT development once the highest-priority indication has been determined. Those assigned priority through the methods described in the preceding section appear above in Table 2. Several of these attributes received intense scrutiny and thus merit additional comment.

Dosage Forms. Given broad consensus that a crucial arbiter of efficacy for any MPT will be adherence to correct product use, it was not surprising that sustained-release devices, importantly intravaginal rings (IVR), were identified as the highest-priority dosage form. The rationale for IVR as a preferred delivery system was that such technologies, which could be user-inserted and designed for at least 30 days of efficacy, offered potential for greater adherence compared to other user-administered systems. IVRs are reversible, may impose less of a burden on health systems and, depending on drug activity, might also mitigate some of the side effects associated with oral administration and correspondingly greater systemic exposure. Again, however, there was variation across survey populations. US providers preferred oral dosage forms, while African providers leaned toward a "suite" of several dosage forms as offering greater potential for acceptability and use, and ranked injection and sustainedrelease devices slightly higher than others.

Efficacy Targets. There was consensus that MPT components for HIV prevention should meet a minimum requirement of $40-50 \%$ reduction in risk, preferably at least $80 \%$ with perfect use and $60 \%$ with typical use. Contraceptive MPT components should be no less effective than currently available products and an efficacy minimum of at least $40 \%$ was the target for prevention of non-HIV STIs.

Product Attributes. Most specific attributes were identified within the context of safety, efficacy, and other factors, with a relatively long shelf life (36 months) and storage at high temperature $\left(40^{\circ} \mathrm{C}\right)$ as the most consistently-supported priorities.

Side Effects. The general view was that these would need to be assessed in the context of the overall safety and anticipated efficacy of the MPT under consideration, but should be "no worse than individual indication products," for example, currently available contraceptives.

Other Parameters. Another group of "non-TPP parameters" emerged in the research and review process as issues requiring further discussion with respect to their importance for different potential user populations. Those were research entity, resupply infrastructure, access to testing/monitoring, cold chain storage (if needed), time to development for compounds, potential drug interactions, mechanism of action established in other products (e.g.,Truvada, NuvaRing), novelty of mechanism of action and enhancement of pipeline diversity, pipeline redundancy, potential for drug resistance, potential for discreet use, influence on sexual experience, incidence/prevalence in target population and overall burden of disease, and few or no existing or readily available treatment options.

\subsection{Multipurpose Reproductive Health (RH) Vaccine Working} Group. The Multipurpose RH Vaccine Working Group's "Request for Concepts" elicited 13 submissions and/or comments, almost all based on active immunization (Table 3 ) and responsive to the Target Product Profile developed by this group (Table 4). Two additional concepts were based on passive immunization [59] and adenovirus vectored antibodies $[60,61]$ and one submission was focused on product development strategies. In general, it was recognized that advances 
in mucosal vaccinology were crucial to advancement of these concepts [62].

4.4. Understanding Regional Needs and Priorities for MPT Development. The information that has accumulated with respect to regional priorities for MPTs has accelerated in volume, coverage and, with the refinement of the Target Product Profiles, its relevance to MPT development writ large. The January 2012 Global Forum on MPTs hosted by the Wellcome Trust was explicitly designed to elicit international multisectoral input into the draft TPPs, extend consideration of the critical path for regulatory approval of MPTs beyond the perspectives of the USFDA to include the views of representatives from other regulatory authorities; encourage a global perspective and international support for this Initiative and seek consensus on next steps, and identify the types of target populations in specific geographic regions most likely to benefit from MPTs. Table 5 summarizes the extensive output of that vital consultation and background material provided by its participants.

4.4.1. The MPT Pipeline. Extensive research by the Scientific Agenda Working Group (SAWG) and colleagues also recently generated the first comprehensive list of all known potential MPT candidate products and components, concepts, relevant technology platforms, and delivery systems responsive to the major MPT indications. The drug candidates in this listing were then subcategorized by mechanism of action, chemical class; product candidates were organized according to dosage form and stage of development. In addition to yielding a summary set of MPT product priorities, this review and analysis process revealed certain imbalances in the R\&D efforts being invested in different MPT product and component types.

4.4.2. Pipeline Prioritization and Gap Identification. Priorities. The exercise to prioritize MPT candidate drugs and products identified specific active pharmaceutical ingredients (API) and product configurations appropriate for timely and effective development of MPT products. In light of the priority indications of HIV and pregnancy prevention, MPTs that involve small organic molecule antiretroviral (ARV) agents and hormonal contraceptives were prioritized. The lack of candidate STI prevention options did not allow for specific prioritization for this indication (see in what follows). Further, it was recognized that a suite of MPT product configurations would be necessary to achieve maximum public health impact. Specifically, vaginal rings, long acting injectables, and alternative on-demand formulations are all defined as priority configurations for MPT products.

Gaps. A range of gaps were identified in the course of the prioritization exercise. Specifically, it was noted in the following:

(i) There is a lack of alternatives to reverse transcriptase inhibitor (RTI) antiretrovirals (ARV) for the HIV indication. (ii) Sufficient understanding of the potential relationship between specific forms of hormonal contraception (e.g., injectable DMPA) and increased risk of HIV transmission is lacking.

(iii) Viable, pathogen-specific options for the non-HIV STI indication for potential MPTs are unavailable.

(iv) There are insufficient data on acceptability, use, and uptake of intravaginal rings.

(v) Too few options for long-acting injectable delivery modalities are in development.

(vi) Insufficient knowledge about the safety of intermittent use of ARVs and other anti-infectives is a risk for on-demand product options in general.

(vii) Limited non-hormonal-contraception and STIprevention options exist.

(viii) Definitive social-behavioral science to support all product options is limited.

Needs. The analysis also generated a short list of earlystage development candidate categories meriting pursuit for possible longer-term development:

(i) STI-specific APIs;

(ii) non-ARV-based HIV prevention;

(iii) lactobacillus-based products;

(iv) nonhormonal contraceptives;

(v) novel on-demand product configurations.

Process Priorities. The product prioritization exercise also generated a set of "process priorities," the absence of which could hinder the MPT effort in the longer term. The key process priority is the need for coordination across donor investments, sponsor development, and program management. This, in general, has been seen as desirable but often absent; however, current resource limitations and the complexities around MPTs dictate the urgency of

(i) consensus on priority products, gaps, and development strategies,

(ii) a coordinated approach to identify single-lead products for each priority MPT product type,

(iii) pooling of capacity, capability, expertise, and other resources between viable development entities interested in MPT products,

(iv) coordinated investment and collaborative/partnered development management,

(v) early and proactive engagement of regulatory authorities, supported by TPP templates specific to product types. 


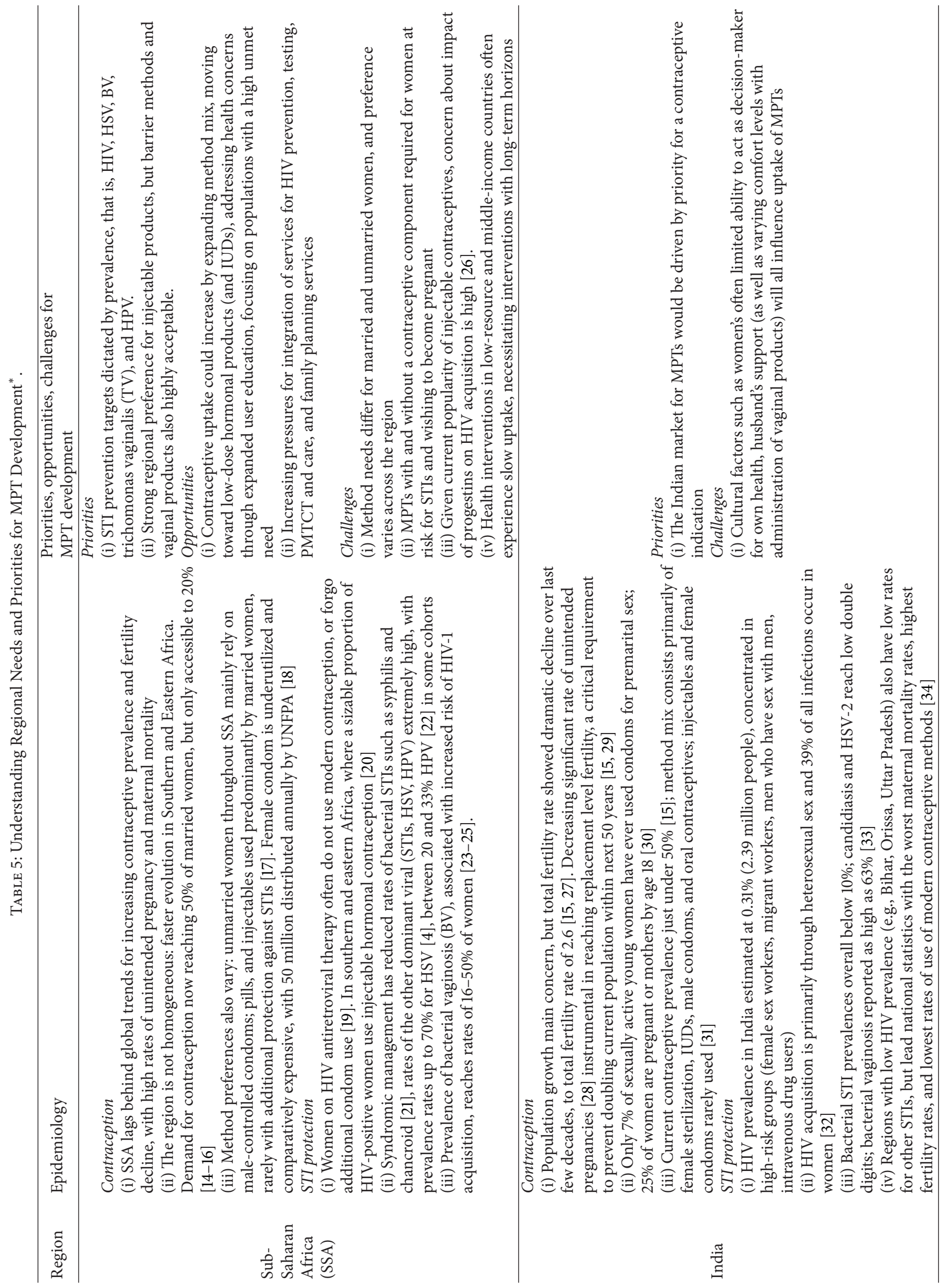




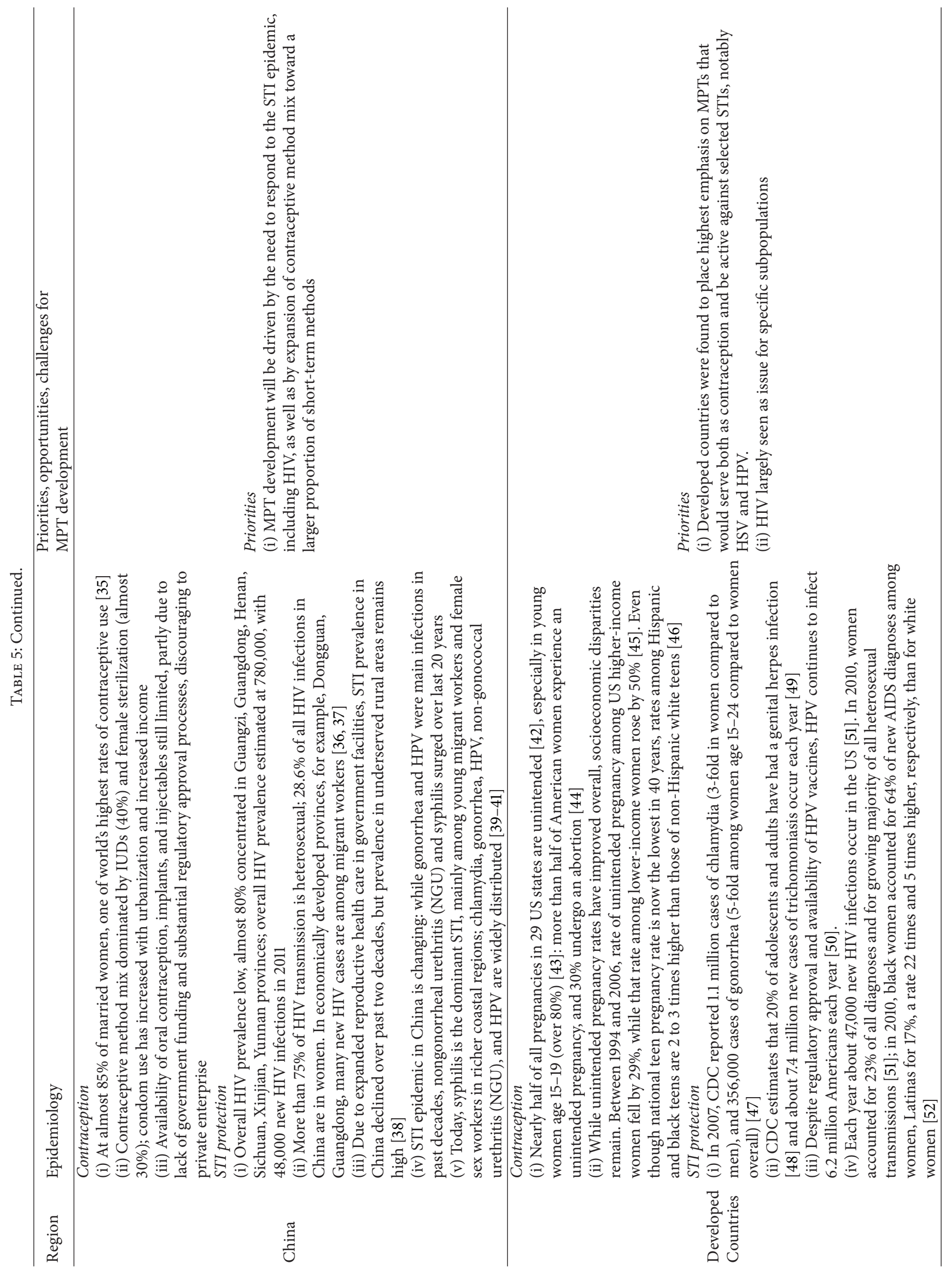




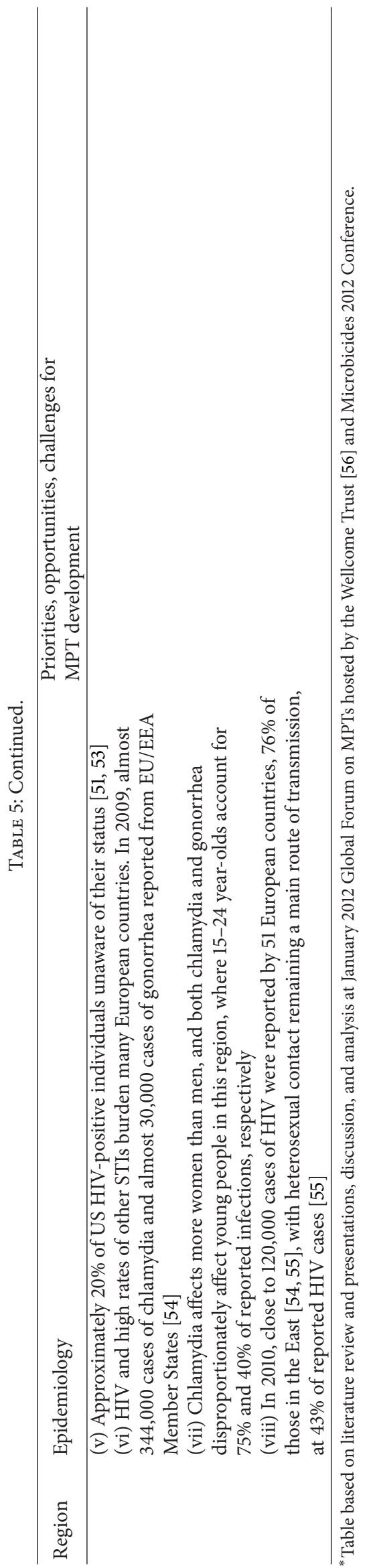




\section{Discussion and Conclusions}

5.1. The State of MPT Research and Development. The purpose of the MPT Scientific Agenda Working Group activities is to inform and provide guidance for donors, product developers, and regulators about MPT priorities and investment needs. It adopted an iterative strategy of steps, feedback loops, adjustments to its own received wisdom and that of others, and an expanding circle of engagement that could inform the process but not cripple it.

The IMPT will continue its iterative process of sharing the priorities identified and associated recommendations, particularly in the area of drug/drug and drug/device combinations, with an expanded range of stakeholders, including regional experts, sociobehavioral scientists, clinicians, and manufacturers. It will also continue to monitor the MPT pipeline and support coordinated donor and developer engagement. As the MPT field advances, MPT product priorities will evolve and expand as the realization of multipurpose reproductive health vaccines, with a longer time line, also proceeds. Both MPT categories are believed to offer considerable potential for innovation, public health impact, and a sizable market in both the developed and developing worlds.

Some critical building blocks are already in place for drug-drug and drug-device MPTs. There are putative MPT components in products long approved for single indications and in contraceptive products already commercially available in multiple configurations. Drugs for treatment of HIV and STI are available, though in some cases imperfect and problematic, and infectious disease prophylaxis is established for some indications. HIV prevention of mother-to-child transmission (PMTCT) is proving effective and results from late-stage trials of Pre-Exposure Prophylaxis of vaginal and oral products suggest that HIV prevention is, with some critical questions to be asked and answered, within reach [63].

A few MPT candidates have completed discovery and are in ongoing development:

(i) an intravaginal ring that continuously releases tenofovir and levonorgestrel from separate ring segments over a period of 90 days, for contraception and HIV prevention [64];

(ii) a gel combining MIV-150, zinc acetate, and carrageenan, with combined activity against HIV and HSV [65];

(iii) a vaginal ring releasing dapivirine and a hormonal contraceptive over 60 days for contraception and HIV prevention [66, 67];

(iv) reformulated tenofovir gel is being studied in conjunction with the existing SILCS diaphragm as a combined barrier contraceptive, adding sperm immobilizing agents and antiviral chemical protection against HIV and HSV [64].

5.2. Allied Efforts. The structure of the Initiative for Multipurpose Prevention Technologies and the work of its colleagues were explicitly designed to take into account that simply having an MPT pipeline and prioritizing R\&D investments would not be sufficient to getting an actual MPT on the market and into the hands of users. Thus, while the activities of the Scientific Agenda Working Group (SAWG) are the focus of this paper, that work could not have evolved nor can it continue without a range of support, importantly including financial resources.

Thus, the Initiative has, through a cross disciplinary approach, implemented a series of activities to support the emerging MPT field and the Scientific Agenda derived from the work of the SAWG. Among those activities are working groups charged with Communications, Advocacy and Outreach and with MPT Acceptability and Access. Both teams aim to increase global awareness and support for MPT development among scientists, donors, policy-makers, regulators, health care providers, and advocates. The Communications, Advocacy and Outreach Working Group has identified and convened regional experts and affiliates in a number of different countries with high unmet need for MPTs (e.g., China, India, Jamaica, Kenya, South Africa, and Tanzania) to help shape the scientific agenda, ensure that the MPTs that are developed will be socially and culturally appropriate and craft messages to raise awareness and support for product research and development. The allied MPT Acceptability and Access Working Group aims to ensure that MPT products will be accessible and affordable for those with highest unmet need, through attention to potential regulatory requirements for MPT products and exploration of the most promising delivery pathways for MPTs in different global regions.

\section{Conclusions}

The road to even the first MPT product will not be smooth. That became clear as the MPT Prioritization Process fulfilled its mandate to highlight key challenges, gaps, and needs if MPTs are to be realized efficiently and with reasonable speed. Different chemical compounds may require different conditions for formulation and release and the human vaginal environment is difficult to mimic accurately in in vitro laboratory or animal experiments. Drug interactions between concurrently released compounds could impact product efficacy and safety. The impact of hormonal contraception on HIV transmission has recently risen to a global level of concern and awaits clarification. There is much to be known about in situ placement of vaginal devices in terms of safety, drug uptake, and distribution, and timely efficacy with respect to prevention. Since women's needs vary in different regions of the world and throughout their lives, a single MPT will not be fully responsive and a "suite" of MPT products will be critical for these new technologies to have optimum public health impact.

Because the prospective user populations for many MPTs reside in a range of economic and epidemiologic settings, review of MPTs will require experts from different fields and collaboration among international regulatory and national health authorities. While the preferential use of already approved drugs and devices as MPT compounds may save time and resources in the navigation of regulatory requirements and although FDA approval for drugs and devices can 
facilitate and accelerate drug approvals in other countries, a comprehensive drug development strategy must nonetheless include regulatory requirements for all target markets.

There are also the linked questions of cost and effectiveness. There is solid evidence for substantial cost savings to be derived from responding to unmet needs for modern contraceptives [2]. Simple modeling exercises indicate that the potential of MPTs to increase product adherence could lead to meaningful positive economic benefits [68].

Advancement of scientific research and public health technologies, particularly innovative technologies for the developing world, has traditionally confronted constraints: insufficient funding, regulatory barriers, private industry perceptions that products designed for the developing world offer scant profit, numerous impediments to product availability, and, sometimes, lack of fit between the technology involved and the population it was meant to benefit. All these constraints have surfaced repeatedly and in some ways uniquely in reproductive health, owing to deep-rooted cultural, political, and socioeconomic factors.

In sum, developing a menu of prevention technologies, indeed even the first such technology, will take years; the perseverance of scientists, donors, and advocates; and the capacity to deal with the inevitable failures inherent in drug development. However, emerging from the most recent conversations hosted by the SAWG was agreement on the requirement to "think big" and resist temptations to settling on refinements of what is already in the pipeline, since multipurpose technologies that simultaneously address two primary reproductive health needs for women worldwide justify the imagination, skills, and sheer grit that will be required for their realization.

\section{Acknowledgments}

For their considerable contributions to the activities that were the foundation for this paper, its authors wish to thank the members of the Initiative for Multipurpose Prevention Technologies (IMPT) and CAMI staff. Particular recognition goes to Elizabeth McGrory, Kathryn Stewart, Martha Brady, Heather Boonstra, Jessica Cohen, Maggie Kilbourne-Brook, Wayne Shields, Alan Stone, and the members of the Scientific Agenda Working Group (SAWG): Diana Blithe, Gina Brown, Nomita Chandhiok, Carolyn Deal, Sinead Delany, Sue Kinn, Judy Manning, Helen Rees, Jim Turpin, Stephen Ward, and Allen Wu. Support for this work was provided by PATH with the generous support of the American people through the United States Agency for International Development (USAID) under the terms of the HealthTech V Cooperative Agreement no. AID-OAA-A-11-00051. Support was also provided by the Bill \& Melinda Gates Foundation and the Mary Wohlford Foundation. The contents of this paper are the responsibility of CAMI, IMPT, and the Public Health Institute and do not necessarily reflect the views of USAID, NIH, or the United States Government.

\section{References}

[1] J. E. Darroch and S. Singh, Estimating Unintended Pregnancies Averted by Couple-Years of Protection (CYP), Guttmacher Institute, New York, NY, USA, 2011.

[2] S. Singh and J. E. Darroch, "Adding It Up: The Costs and Benefits of Investing in Family Planning and Maternal and Newborn Health. Guttmacher Institute and United Nations Population Fund (UNFPA)," 2009, http://www.guttmacher.org/pubs/ AIU-2012-estimates.pdf.

[3] World Health Organization, "Sexually transmitted infections: Fact Sheet No. 110," 2011, http://www.who.int/mediacentre/ factsheets/fs110/en/.

[4] K. J. Looker, G. P. Garnett, and G. P. Schmid, "An estimate of the global prevalence and incidence of herpes simplex virus type 2 infection," Bulletin of the World Health Organization, vol. 86, no. 10, pp. 805-812, 2008.

[5] WHO/ICO Information Centre on HPV and Cervical Cancer (HPV Information Centre), "Human Papillomavirus and Related Cancers in World. Summary Report 2010," 2010, http:// hpv2010.org/main/images/stories/docs/HPVInformationCentre_SummaryReportWorld_Feb2010.pdf.

[6] D. T. Fleming and J. N. Wasserheit, "From epidemiological synergy to public health policy and practice: the contribution of other sexually transmitted diseases to sexual transmission of HIV infection," Sexually Transmitted Infections, vol. 75, no. 1, pp. 3-17, 1999.

[7] Cohen and MS, "Classical sexually transmitted diseases drive the spread of HIV-1: back to the future," The Journal of Infectious Diseases, vol. 206, no. 1, pp. 1-2, 2012.

[8] J. Stover, L. Dougherty, and M. Hamilton, "Are Cost Savings Incurred by Offering Family Planning at Emergency Plan HIV/AIDS Care and Treatment Facilities?” Futures Group/ POLICY Project, Washington, DC, USA, 2006, http://www .policyproject.com/pubs/generalreport/FP-HIV\%20Integration\%20Costs\%20and\%20Savings\%20Final.pdf.

[9] A. Tong, P. Sainsbury, and J. Craig, "Consolidated criteria for reporting qualitative research (COREQ): a 32-item checklist for interviews and focus groups," International Journal for Quality in Health Care, vol. 19, no. 6, pp. 349-357, 2007.

[10] Population Council, "Facilitating Regulatory Approval of Multipurpose Prevention Technologies (MPTs) for Reproductive Health Day of Dialogue on Multipurpose Preve ntion Technologies: Toward Clarity in Nomenclature," 2011, http://camihealth.org/documents/2011DayOfDialogueNomenclature_Report.pdf.

[11] Coalition Advancing Multipurpose Innovations (CAMI), "Multipurpose Prevention Technologies for Reproductive Health: Advancing the Scientific and Product Development Agenda Report of a "Think Tank"', 2011, http://www.cami-health.org/ documents/050511-MPT-ThinkTank.pdf.

[12] Coalition Advancing Multipurpose Innovations (CAMI), "Multipurpose Prevention Technologies for Reproductive Health 2011 Symposium," 2011, http://cami-health.org/documents/MPT2011-Symposium-Report.pdf.

[13] Coalition Advancing Multipurpose Innovations (CAMI), "Global Forum on Multipurpose Prevention Technologies for Reproductive Health," 2011, http://cami-health.org/documents/ 2012-Global-Forum-Report.pdf.

[14] K. Rawe, A. Dunford, J. Stewart, J. Espey, and J. Stoeckel, "Every Woman's Right. London: Save the Children UK," 2012, http:// www.savethechildren.org/atf/cf/\%7B9def2ebe-10ae-432c-9b 
d0-df91d2eba74a\%7D/EVERY_WOMANS_RIGHT_REPORT_ JUNE_2012.PDF.

[15] Population Reference Bureau, "World Population Data Sheet," 2011, http://www.prb.org/pdf11/2011population-datasheet_eng.pdf.

[16] Guttmacher Institute and International Planned Parenthood Federation, "Facts on Satisfying the Need for Contraception in Developing Countries," November 2010, http://www.imea.fr/ imea-fournier/imea-fournier-2010/101122-c-Contraception-PVD.pdf.

[17] ORC Macro, "Demographic and Health Surveys 2004-1010," Calverton, Md, USA, 2013, http://www.measuredhs.com.

[18] UNFPA, "Contraceptive Commodities for Women's Health. Report for UN Commission on Lifesaving commodities for Women and Children," 2012, http://www.unfpa.org/webdav/ site/global/shared/images/publications/2012/UN\%20Commission_\%20FP\%20Synthesis_\%20Final\%2019\%20March\%20 2012.pdf.

[19] S. R. Schwartz, H. Rees, S. Mehta, W. D. Venter, T. E. Taha, and V. Black, "High incidence of unplanned pregnancy after antiretroviral therapy initiation: findings from a prospective cohort study in South Africa," PLoS ONE, vol. 7, no. 4, Article ID e36039, 2012.

[20] A. R. Butler, J. A. Smith, C. B. Polis, S. Gregson, D. Stanton, and T. B. Hallett, "Modelling the global competing risks of a potential interaction between injectable hormonal contraception and HIV risk," AIDS, vol. 27, no. 1, pp. 105-113, 2013.

[21] L. F. Johnson, R. E. Dorrington, D. Bradshaw, and D. J. Coetzee, "The effect of syndromic management interventions on the prevalence of sexually transmitted infections in South Africa," Sexual and Reproductive Healthcare, vol. 2, no. 1, pp. 13-20, 2011.

[22] WHO/ICO HPV Information Centre, "Human Papillomavirus and Related Cancers in Africa. Summary Report 2010. Table 1: Key statistics in Africa and its regions," 2010.

[23] C. R. Cohen, J. R. Lingappa, J. M. Baeten et al., "Bacterial vaginosis associated with increased risk of female-to-male HIV1 transmission: a prospective cohort analysis among African couples," PLoS Medicine, vol. 9, no. 6, Article ID e1001251, 2012.

[24] L. Myer, L. Denny, R. Telerant, M. De Souza, T. C. Wright, and L. Kuhn, "Bacterial vaginosis and susceptibility to HIV infection in South African women: a nested case-control study," Journal of Infectious Diseases, vol. 192, no. 8, pp. 1372-1380, 2005.

[25] M. E. Thoma, R. H. Gray, N. Kiwanuka, M. C. Wang, N. Sewankambo, and M. J. Wawer, "The natural history of bacterial vaginosis diagnosed by gram stain among women in Rakai, Uganda," Sexually Transmitted Diseases, vol. 38, no. 11, pp. 10401045, 2011.

[26] R. Heffron, D. Donnell, H. Rees et al., "Use of hormonal contraceptives and risk of HIV-1 transmission: a prospective cohort study," The Lancet Infectious Diseases, vol. 12, no. 1, pp. 19-26, 2012.

[27] Office of Registrar General India, "Maternal \& Child Mortality and Total Fertility Rates Sample Registration System (SRS)," 2011, http://censusindia.gov.in/vital_statistics/ SRS_Bulletins/MMR_release_070711.pdf.

[28] M. A. Koenig, R. Acharya, T. K. Roy, and S. Singh, "The Measurement of Unintended Pregnancy in Rural India: A Comparison of Prospective versus Retrospective Assessment," Bloomberg School of Public Health, The Johns Hopkins University (USA) and International Institute for Population Sciences, Mumbai (India). Abstract at PAA 2005,
http://paa2005.princeton.edu/download.aspx?submissionId= 51322 .

[29] International Institute for Population Sciences (IIPS) and Macro International, "National Family Health Survey (NFHS3), 2005-06: India: Volume I," Mumbai: IIPS, 2007, http:// www.measuredhs.com/pubs/pdf/FRIND3/FRIND3-VollAnd Vol2.pdf.

[30] K. G. Santhya, R. Acharya, S. J. Jejeebhoy, and U. Ram, “Timing of first sex before marriage and its correlates: evidence from India," Culture, Health and Sexuality, vol. 13, no. 3, pp. 327-341, 2011.

[31] International Institute for Population Sciences (IIPS), "District Level Household and Facility Survey (DLHS-3), 200708: India," Mumbai: IIPS, 2010, http://www.rchiips.org/pdf/ http://www.rchiips.org/pdf/INDIA_REPORT_DLHS-3.pdf.

[32] AVERT, "India HIV \& AIDS Statistics," 2013, http://www.avert .org/india-hiv-aids-statistics.htm.

[33] National Aids Control Organisation (NACO). Ministry Of Health and Family Welfare. Government of India, "HIV Sentinel Surveillance and HIV Estimation in India 2007. A Technical Brief," 2008, http://nacoonline.org/upload/Publication/M\&E\%20Surveillance,\%20Research/HIV\%20Sentinel\% 20Survei-llance\%20and\%20HIV\%20Estimation\%202007_A\% 20Technical\%20Brief.pdf.

[34] National Aids Control Organisation (NACO). Ministry Of Health and Family Welfare. Government of India, "National Aids Control Programme III. Report on Mid-Term Review of Sexually Transmitted Infection Services," 2009, http:// nacoonline.org/upload/STI\%20RTI\%20services/STI\%20RTI\% 20MONOGRAPH\%20_NACP-III-.pdf.

[35] R. Will, "Contraceptive Use in China. US-China Today. University of Southern California US-China Institute," 2012, http:// www.uschina.usc.edu/w_usci/showarticle.aspx?articleID $=180$ 21\&AspxAutoDetectCookieSupport=1.

[36] Ministry of Health of the People\&\#x27;s Republic of China, "2012 China AIDS Response Progress Report," 2012, http:// www.unaids.org/en/dataanalysis/monitoringcountryprogress/ progressreports/2012countries/ce_CN_Narrative_Report[1] .pdf.

[37] UNGASS, "China 2010 UNGASS Country Progress Report (2008-2009)," 2010, http://data.unaids.org/pub/Report/2010/ china_2010_country_progress_report_en.pdf.

[38] X. Qian, S. Tang, and P. Garner, "Unintended pregnancy and induced abortion among unmarried women in China: a systematic review," BMC Health Services Research, vol. 4, article 1, pp. 1-4, 2004.

[39] X. Fang, Y. Zhou, Y. Yang, Y. Diao, and H. Li, "Prevalence and risk factors of trichomoniasis, bacterial vaginosis, and candidiasis for married women of child-bearing age in rural Shandong," Japanese Journal of Infectious Diseases, vol. 60, no. 5, pp. 257-261, 2007.

[40] C. Li, H. R. Han, J. E. Lee, M. Lee, Y. Lee, and M. T. Kim, "Knowledge, behaviors and prevalence of reproductive tract infections: a descriptive study on rural women in Hunchun, China," Asian Nursing Research, vol. 4, no. 3, pp. 122-129, 2010.

[41] X. J. Zhang, Q. Shen, G. Y. Wang et al., "Risk factors for reproductive tract infections among married women in rural areas of Anhui Province, China," European Journal of Obstetrics Gynecology and Reproductive Biology, vol. 147, no. 2, pp. 187-191, 2009. 
[42] L. B. Finer and K. Kost, "Unintended Pregnancy Rates at the State Level," Perspectives on Sexual and Reproductive Health, vol. 43, no. 2, pp. 78-87, 2011.

[43] K. Kost, S. Henshaw, and L. Carlin, "U.S. Teenage Pregnancies, Births and Abortions: National and State Trends and Trends by Race and Ethnicity," 2010, Guttmacher Institute, http://www.guttmacher.org/pubs/USTPtrends.pdf.

[44] R. K. Jones and M. L. Kavanaugh, "Changes in abortion rates between 2000 and 2008 and lifetime incidence of abortion," Obstetrics \& Gynecology, vol. 117, no. 6, pp. 1358-1366, 2011.

[45] L. B. Finer and M. R. Zolna, "Unintended pregnancy in the United States: incidence and disparities," Contraception, vol. 85, no. 5, pp. 478-485, 2006.

[46] K. Kost and S. Henshaw, "U.S. Teenage Pregnancy, Births, and Abortions, 2008: National Trends by Age, Race, and Ethnicity," Guttmacher Institute, February 2012.

[47] Centers for Disease Control and Prevention, "Chlamydia screening among sexually active young female enrollees of health plans-United States, 2000-2007," Morbidity and Mortality Weekly Report, vol. 58, no. 14, pp. 362-365, 2009.

[48] Centers for Disease Control and Prevention, "Genital herpes. CDC Fact Sheet," December 2007, http://www.cdc.gov/ std/Herpes/STDFact-Herpes.htm.

[49] Centers for Disease Control and Prevention, "Trichomoniasis, CDC Fact Sheet," December 2007, http://www.cdc.gov/ std/trichomonas/STDFact-Trichomoniasis.htm.

[50] Centers for Disease Control and Prevention, "Genital HPV infection. CDC Fact Sheet," May 2004, http://www.cdc.gov/ std/HPV/STDFact-HPV.htm.

[51] Centers for Disease Control and Prevention, "HIV in the United States: At A Glance," 2012 http://www.cdc.gov/hiv/resources/factsheets/PDF/HIV_at_a_glance.pdf.

[52] Centers for Disease Control and Prevention, Morbidity and Mortality Weekly Report, vol. 60, no. 31, 2011.

[53] Centers for Disease Control and Prevention, "HIV/AIDS in the United States, CDC HIV/AIDS Facts," 2008, http:// www.cdc.gov/hiv/resources/factsheets/us.htm.

[54] European Centre for Disease Prevention and Control, "Sexually Transmitted Infections in Europe, 1990-2009," Stockholm: ECDC, 2011.

[55] European Centre for Disease Prevention and Control/WHO Regional Office for Europe, "HIV/AIDS surveillance in Europe 2010," Stockholm: ECDC, 2011.

[56] P. W. Tebbey and C. Rink, "Target product profile: a renaissance for its definition and use," Journal of Medical Marketing, vol. 9, no. 4, pp. 301-307, 2009.

[57] A. Stone, "Advancing Prevention Technologies for Sexual and Reproductive Health," Report of a 2009 Symposium in Berkeley, Calif, USA, http://cami-health.org/resources/reports.php.

[58] US Food and Drug Administration (USFDA), Center for Drug Evaluation and Research, "Guidance for Industry and Review Staff: Target Product Profile-A Strategic Development Process Tool," Draft Guidance, March 2007, http://www .fda.gov/downloads/Drugs/GuidanceComplianceRegulatory Information/Guidances/ucm080593.pdf.

[59] The Collaboration for AIDS Vaccine Discovery, "Topic 4 Overview: Passive Immunization with Human Monoclonal Antibodies for HIV Prevention. Diversifying the Pipeline of Product Concepts for an HIV Vaccine: RFP Overview and Guidelines," Bill \& Melinda Gates Foundation, 2010.
[60] A. B. Balazs, J. Chen, C. M. Hong, D. S. Rao, L. Yang, and D. Baltimore, "Antibody-based protection against HIV infection by vectored immunoprophylaxis," Nature, vol. 481, no. 7379, pp. 81-84, 2011.

[61] U. M. Abdel-Motal, P. T. N. Sarkis, T. Han et al., "Anti-gp120 minibody gene transfer to female genital epithelial cells protects against HIV-1 virus challenge in vitro," PLoS ONE, vol. 6, no. 10, Article ID e26473, 2011.

[62] J. Mestecky, M. Raska, J. Novak, R. C. Alexander, and Z. Moldoveanu, "Antibody-mediated protection and the mucosal immune system of the genital tract: relevance to vaccine design," Journal of Reproductive Immunology, vol. 85, no. 1, pp. 81-85, 2010.

[63] D. R. Friend, "Drug delivery in multiple indication (multipurpose) prevention technologies: systems to prevent HIV-1 transmission and unintended pregnancies or HSV-2 transmission," Expert Opinion on Drug Delivery, vol. 4, no. 9, pp. 417-427, 2012.

[64] CONRAD, "Online information on current research efforts regarding MPTs," 2013, http://www.conrad.org/research-technologies.html.

[65] J. Kenney, R. Singer, N. Derby et al., "A single dose of a MIV$150 / Z i n c$ acetate gel provides $24 \mathrm{~h}$ of protection against vaginal simian human immunodeficiency virus reverse transcriptase infection, with more limited protection rectally 8-24 h after gel use," AIDS Research and Human Retroviruses, vol. 28, no. 11, pp. 1476-1484, 2012.

[66] International Partnership for Microbicides, "A microbicide ring to protect against HIV," http://www.dfid.gov.uk/r4d/PDF/Outputs/Microbicides/RING_BACKGROUNDER_\%20ENGLISH .pdf.

[67] Population Council, "Critical issues for integrating SRH and HIV/AIDS services to provide dual protection against unintended pregnancy and HIV/STI acquisition," http:// www.popcouncil.org/pdfs/events/2012ICCR_Brache.pdf, http://.popcouncil.org/pdfs/2012RH_STEPUPSymposiumReport.pdf.

[68] J. Romano, "High-impact products: necessary attributes, development prospects, and challenges," in Presentation at Symposium 6: Prevention of Multiple Reproductive Health Indications, Microbicides 2012 Conference, Sydney, Australia, April 2012, http://cami-health.org/convenings/Microbicides-2012.php. 


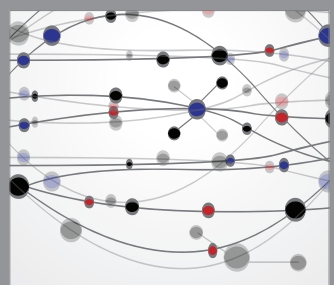

The Scientific World Journal
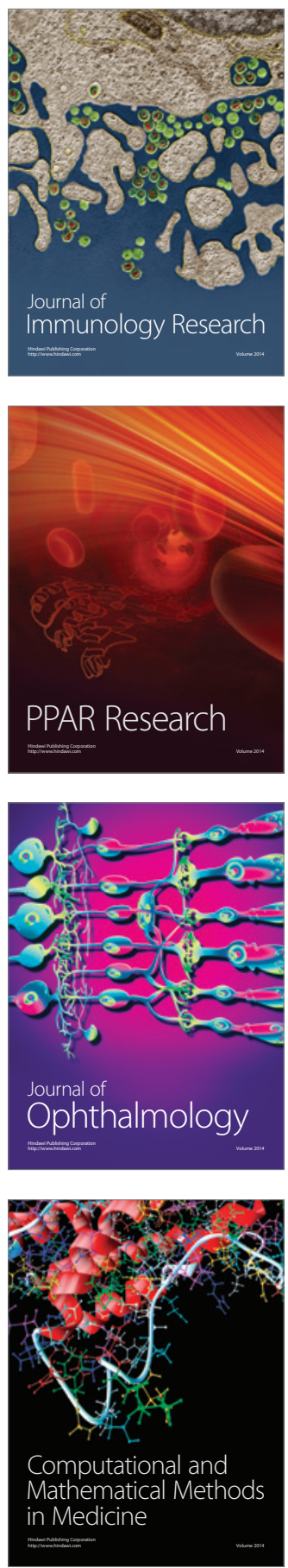

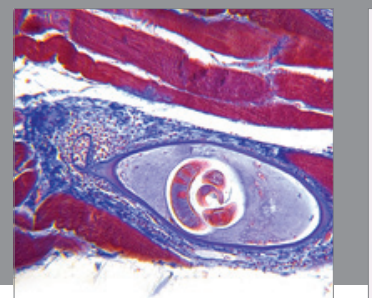

Gastroenterology

Research and Practice
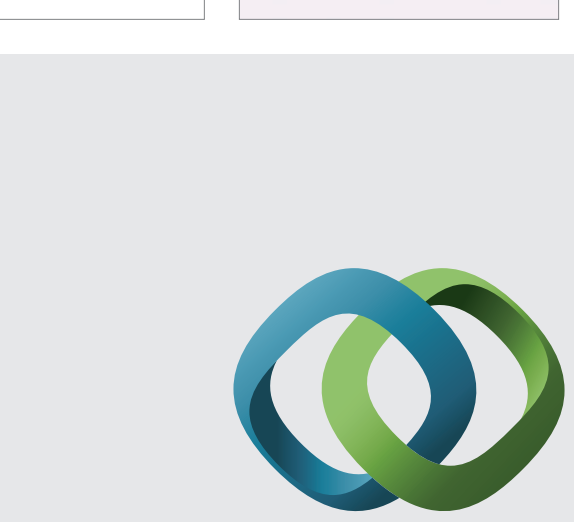

\section{Hindawi}

Submit your manuscripts at

http://www.hindawi.com
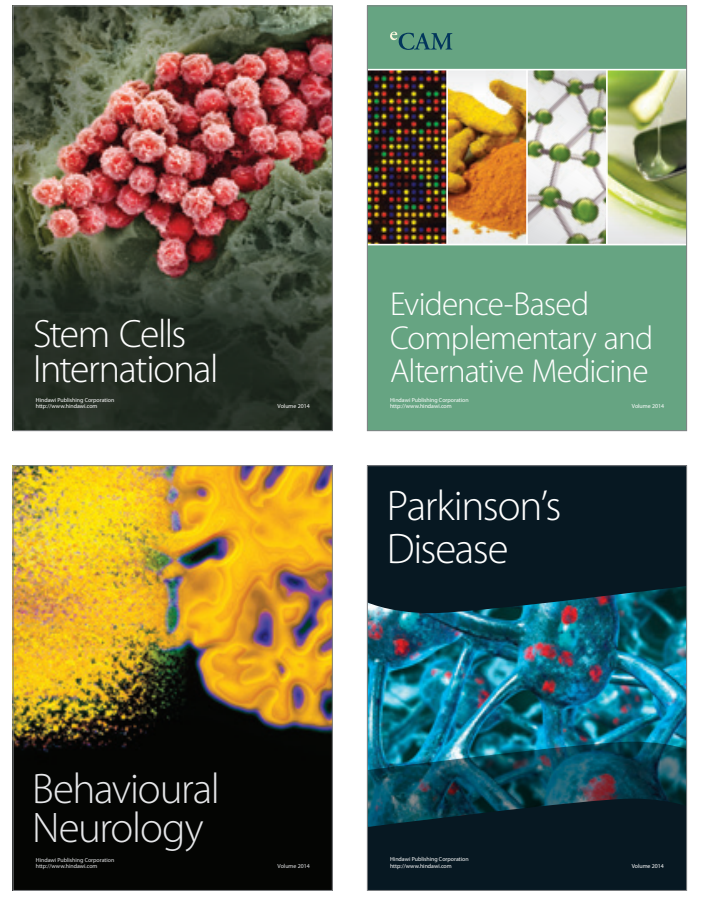
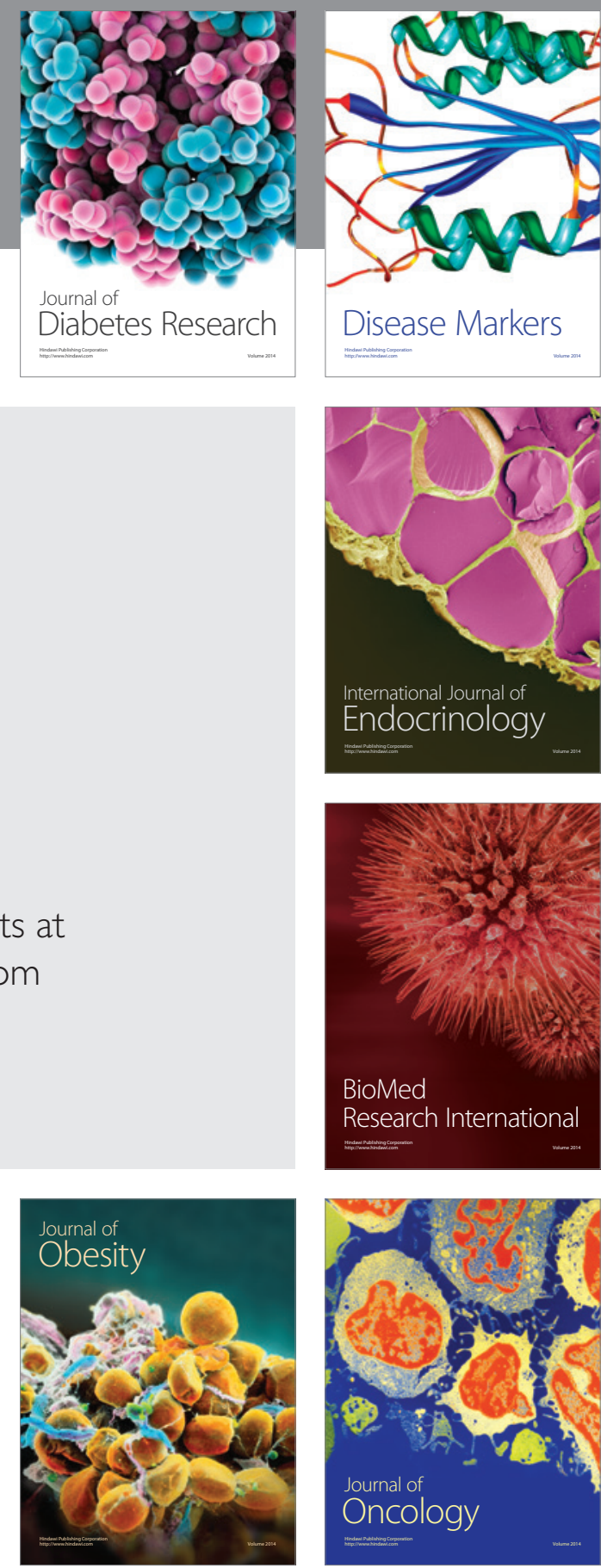

Disease Markers
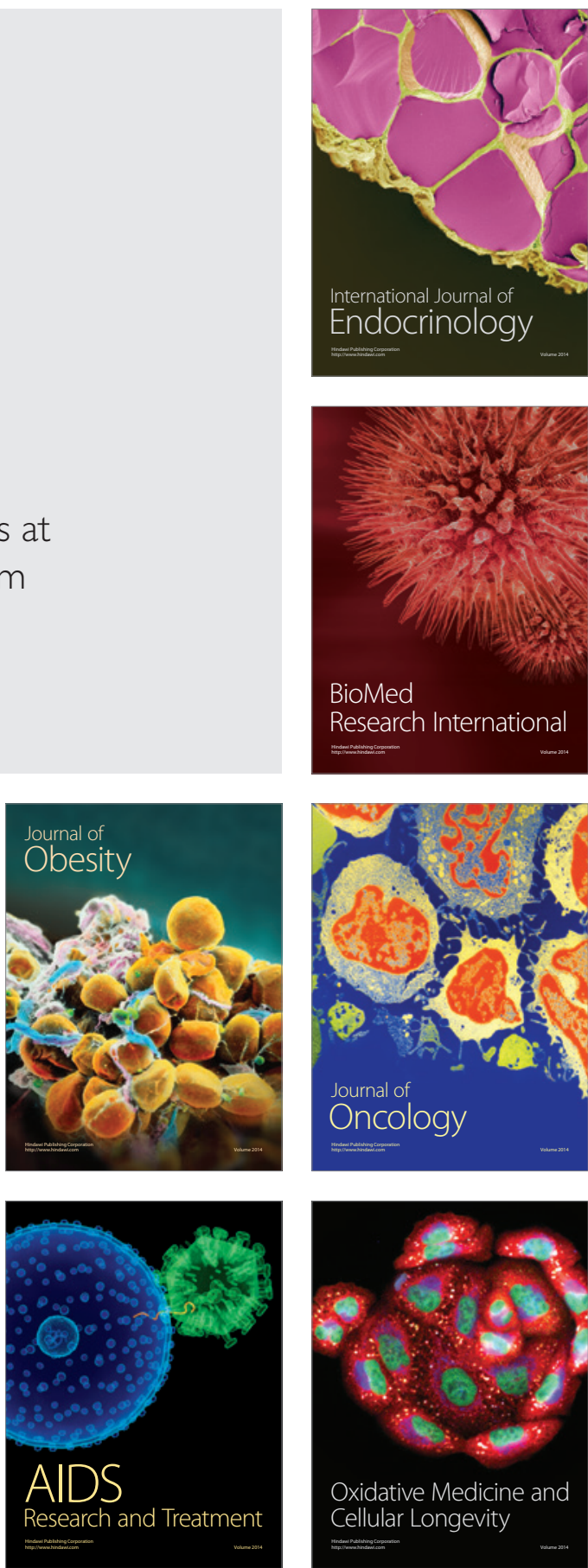